\title{
Panorama da gestão de resíduos em Volta Redonda/RJ
}

Overview of waste management in Volta Redonda / RJ

1 Francisco Jácome Gurgel Júnior gurgel.j@gmail.com

1 Professor do curso de Engenharia Ambiental e Engenharia Civil do UniFOA e da Secretaria Estadual de Educação do Rio de Janeiro (SEEDUC/RJ).

\section{Resumo}

A elevada geração de resíduos e rejeitos e sua destinação incorreta no mundo pelos mais de sete bilhões de habitantes do planeta têm provocado inúmeros impactos ambientais negativos de grande magnitude sobre os recursos ambientais existentes e que são decorrência da ausência ou ineficácia dos gestores públicos pelo descumprimento da legislação concernente, dos planos de controle de resíduos em suas respectivas jurisdições, bem como do desconhecimento e falta de envolvimento da sociedade em geral. Em Volta Redonda/RJ, maior cidade da região Sul Fluminense, a situação não é diferente e faz-se urgente a elaboração e implementação do Plano Municipal de Gestão Integrada de Resíduos Sólidos, para cumprimento da novel Política Nacional de Resíduos Sólidos, consubstanciada pela lei federal $n^{0} 12.305 / 10$, e seu decreto regulamentador, que incumbe o município dessa importante responsabilidade. A pesquisa ora proposta tem como objetivo maior a análise geral da gestão de resíduos promovida pela Prefeitura Municipal de Volta Redonda através da Secretaria Municipal de Serviços Públicos, identificação de suas respectivas fragilidades e potencialidades, incluindo a Coleta Seletiva existente, o encerramento do lixão outrora utilizado para a disposição dos resíduos sólidos urbanos, bem como as perspectivas futuras, quando da implementação do Plano Municipal de Gestão Integrada de Resíduos Sólidos e seus instrumentos pela coleta de informações, entrevistas, visitas técnicas, consulta à legislação pertinente e demais documentos de interesse.

\section{Palavras-chave}

Panorama. Gestão de resíduos. PMGIRS. Volta Redonda.

\begin{abstract}
The high generation of wastes and tailings and their incorrect disposal in the world by the more than seven billion inhabitants of the planet have caused numerous negative environmental impacts of great magnitude on the existing environmental resources and that are due to the absence or inefficacy of the public managers by the noncompliance of the Legislation, waste control plans in their respective jurisdictions, as well as the lack of knowledge and lack of involvement of society in general. In Volta Redonda / RJ, the largest city in the South Fluminense region, the situation is no different and it is urgent to elaborate and implement the Municipal Solid Waste Management Plan to comply with the new National Solid Waste Policy, consolidated by Federal Law No. 12,305 / 10 and its regulatory decree that is the responsibility of the municipality of this important responsibility. The research proposed here has as its main objective the general analysis of waste management promoted by the Municipal Government of Volta Redonda through the Municipal Public Services Department, identification of their respective fragilities and potentialities, including existing Selective Collection, closure of the previously used dump For the disposal of municipal solid waste, as well as future perspectives when implementing the Municipal Integrated Solid Waste Management Plan and its instruments for the collection of information, interviews, technical visits, consultation of pertinent legislation and other documents of interest.
\end{abstract}

\section{Keywords}

Panorama; Waste Management; PMGIRS; Volta Redonda.

\section{Como você deve citar?}

JÚNIOR, Francisco Jácome Gurgel. Panorama da gestão de resíduos em Volta Redonda/RJ. Cadernos UniFOA, Volta Redonda, n. 35, p. 35-46, dez. 2017. 


\section{INTRODUÇÃO}

Esta pesquisa tem por finalidade avaliar a gestão de resíduos sólidos praticada pela Prefeitura Municipal de Volta Redonda (PMVR), através da Secretaria Municipal de Serviços Públicos (SMSP), da Secretaria Municipal de Meio Ambiente (SMMA) e da Secretaria Municipal de Ação Comunitária (SMAC), suas respectivas fragilidades e potencialidades, visto que, com a promulgação da Política Nacional de Resíduos Sólidos (PNRS- Lei Federal n 12.305/10), os municípios terão que obrigatoriamente formular os seus respectivos Planos Municipais de Gerenciamento Integrado de Resíduos Sólidos. Com a execução desses planos, o Poder Executivo local deve assumir definitivamente a adoção de medidas preventivas e corretivas para eliminaçãodos impactos ambientais negativos provenientes da omissão e/ou gestão inadequada dos resíduos e rejeitos gerados nos territórios sob sua responsabilidade e praticar em sua totalidade os instrumentos previstos em lei.

Segundo a ABRELPE (2015), cerca de 82.000 toneladas de resíduos sólidos urbanos ainda são enviados irregularmente para lixões e aterros controlados por 3.334 municípios. Historicamente, desde que os seres humanos começaram a se agrupar e viver em cidades, sempre existiu a produção de resíduos, essencialmente compostos por matéria orgânica. Os cuidados com os resíduos já foram abordados em escritos hebreus há mais de cinco mil anos. Assim, colocar fora das aldeias os resíduos, cobri-los ou enterrá-los é usual, desde que os seres humanos começaram a viver em grupo (MAHLER et al., 2002).

O controle ambiental de resíduos e rejeitos é de extrema importância para minimização e controle de seus inúmeros impactos ambientais negativos advindos de sua disposição inadequada em lixões. Gerir seus respectivos resíduos sólidos urbanos com responsabilidade e técnica apropriada é o grande desafio para a maioria absoluta dos municípios brasileiros nesta década, que ainda despejam esses resíduos em lixões e aterros controlados, provocando a degradação do solo edo subsolo, a contaminação dos recursos hídricos, fauna, flora, bacia aérea e demais componentes da paisagem.

\section{REVISÃo BIBLIOGRÁFICA}

Yoshida (2012) endossa que deve haver corresponsabilidade na gestão compartilhada do meio ambiente entre o Poder Público e a sociedade, para fins de sua mais eficiente proteção e defesa e que essa inovação se situa no contexto da evolução da tutela dos direitos difusos em geral, incorporada pela Constituição de 1988 (art. 225, caput) e, cada vez mais, pelas legislações ambientais, como é o caso da avançada lei federal $n^{\circ} 12.305 / 10$, que institui a PNRS.

Monterosso (2016) argumenta que os Planos Municipais de Gerenciamento Integrado de Resíduos Sólidos são uma ferramenta indispensável no manejo e na gestão dos resíduos sólidos no município e que, além de promoverem um diagnóstico da situação dos resíduos sólidos gerados, contemplam possibilidades de implantação de soluções integradas para os diversos tipos de resíduos gerados.

Ao contrário do que se poderia imaginar intuitivamente, os resíduos sólidos urbanos são produzidos em menor escala que os resíduos industriais. Incluem-se, nessa categoria, os resíduos domiciliares, o resíduo comercial (produzido, por exemplo, em escritórios, lojas, hotéis, supermercados e restaurantes), os resíduos de serviços oriundos da limpeza pública urbana, como, por exemplo, os resíduos de varrição das vias públicas, da limpeza de galerias, terrenos, córregos, praias, feiras e das podas. Os resíduos urbanos são de responsabilidade das prefeituras (TENÓRIO \& ESPINOSA, apud PHILLIPI JR. et al., 2004).Por isso, deveriam ser integrados como matérias-primas nos ciclos produtivos ou na natureza (IDEC \& MMA, 2005). 0 gerenciamento integrado do lixo municipal é um conjunto articulado de ações normativas, operacionais, financeiras e de planejamento que uma administração municipal 
desenvolve (com base em critérios sanitários, ambientais e econômicos), para coletar, segregar, tratar e dispor o lixo das cidades (CEMPRE, 2010).

Marques (2010) advoga que os depósitos de lixo, conhecidos popularmente como "lixões", constituem-se hoje em verdadeira ameaça ao meio ambiente, notadamente porque já esgotaram sua capacidade de armazenamento e porque não recebem qualquer tratamento visando a minimizar a degradação já provocada e que ainda provocam no meio. Botkin \& Keller (2011) deduzem que a disposição ilegal de resíduos sólidos é um problema social, assim como um problema físico, porque muitas pessoas estão simplesmente descartando os seus resíduos da forma mais barata e rápida possível e que a maioria desconhece que seu lixo é um grave problema ambiental, além de desperdício de recursos, pois muito do que é queimado poderia ser reciclado.

Machado (2010) assevera que os resíduos sólidos têm sido negligenciados tanto pelo público como pelos legisladores e administradores, devido provavelmente à ausência de divulgação de seus efeitos poluidores, e que os resíduos sólidos têm sido menos irritante que os resíduos líquidos e gasosos, porque colocado na terra não se dispersa amplamente, como os poluentes do ar e da água.

O Ministério das Cidades (2005) acentua que, em áreas urbanas, os principais problemas de saneamento relacionados com a gestão de resíduos sólidos são: os resíduos sólidos não coletados; o aumento do risco de inundações, em razão dos distúrbios que os resíduos sólidos não coletados geram; a ausência de aterros sanitários e a ocorrência frequente de lixões e aterros não controlados; a disposição final inadequada de resíduos sólidos especiais, como os resíduos industriais, os hospitalares e os de construção civil, como entulhos; a presença de catadores de material reciclável, muitas ainda crianças e adolescentes, trabalhando em condições insalubres nos lixões e nas ruas; e baixos índices de reutilização e reciclagem, que se dá sem apoio do poder público.

Souza (2010) assevera que o lixo é um problema grave e exige solução, pois a questão ambiental está intimamente ligada à viabilidade da própria vida no planeta, isto é, se medidas eficazes não forem tomadas no sentido de solucionar a questão em torno dos resíduos sólidos produzidos nas cidades, estarão comprometidos o bem-estar e a qualidade de vida dos habitantes da urbe, com reflexos negativos em seu modo de ser e viver.

\section{MATERIAL E MÉTODOS}

Em Volta Redonda, a gestão de resíduos sólidos urbanos (RSUs) é formulada, fiscalizada, coordenada e realizada pela Secretaria Municipal de Obras e Serviços Públicos (SMOSP) que relaciona em seu sítio eletrônico (http://www.voltaredonda.rj.gov.br/smo/) os serviços prestados: varrição de ruas e praças, capina, roçada e limpeza (manual), capina química, coleta de lixo (domiciliar, comercial, hospitalar e industrial), instalação de papeleiras em locais de grande fluxo de pedestres, recolhimento de terra e entulhos, fornecimento de caçamba coletoras de entulho, recolhimento de animais mortos (pequeno e grande porte) e seu devido enterramento, limpeza manual de rios e canais, caiação (vias, logradouros públicos, postes, praças, jardins, canteiros e demais áreas verdes do município), coleta de resíduos patogênicos e manutenção do vazadouro municipal (transporte e destinação final do lixo coletado (PREFEITURA MUNICIPAL DE VOLTA REDONDA, 2011).

A Secretaria Municipal de Obras e Serviços Públicos de Volta Redonda localiza-se na rua Pitágoras, $n^{\circ} 59$, bairro Retiro. Além dos serviços acima relacionados, cita os projetos VR Limpa e VR Verde que apresentam como objetivos, respectivamente, a disponibilização de caçambas para retirada de entulhos 
e a revitalização de toda a cidade com plantio de flores e árvores. Menciona ainda a coleta seletiva no município em um link que não funciona (não possibilita acesso à informação).

Segundo Vesilind \& Morgan (2011), a população pode utilizar três alternativas para se livrar de seu material indesejado, quando gerado - reutilização, reciclagem e descarte. Na reutilização, um indivíduo usa os produtos novamente para a mesma finalidade ou os coloca para um segundo uso, frequentemente criativo, enquanto na reciclagem ou na recuperação do material, há coleta de resíduos e seu subsequente processamento em novos produtos.

\subsection{O Lixão de Volta Redonda}

O antigo lixão de Volta Redonda fica localizado nas proximidades da rodovia municipal Tancredo Nevese o acesso ao local é feito, a partir do centro de Volta Redonda, tomando-se inicialmente a rodovia municipal Tancredo Neves ou VRD-001, estrada pavimentada que liga a cidade à rodovia Presidente Dutra (BR-116). A entrada do extinto lixão é o depósito da fábrica Panco, uma estrada não pavimentada que dá acesso a ele, confinando com o clube Português, com uma extensão de, aproximadamente, 300 metros.

Segundo Setta (2016), a área total do lixão é de $175.950 \mathrm{~m}^{2}$, sendo que a área do maciço é de $57.103 \mathrm{~m}^{2}$. A operação do vazadouro foi feita pelo município de Volta Redonda e ocorreu durante o período compreendido entre 1987 e 2012. O lixão de Volta Redonda foi declarado de utilidade pública para fins de desapropriação, conforme os Decretos Executivos Municipais n 8.707 e 8.708, ambos de 28 de setembro de 2000 e Decreto n 8.784 de 19 de dezembro de 2000.

Há de se ressaltar que a área selecionada está localizada no entorno da Área de Relevante Interesse Ecológico (ARIE) da Floresta da Cicuta, conforme Decreto Federal n 90.792/85, que dispõe sobre a criação da referida unidade de conservação, considerada Área de Preservação Ambiental (APA), pelo Decreto Municipal $\mathrm{n}^{\circ}$ 4.752, de 02 de abril de 1993.A municipalidade de Volta Redonda operava 0 lixão (Fig. 01), desde 1987, sem o devido licenciamento ambiental, encravado no entorno da ARIE (Área de Relevante Interesse Ecológico) da Floresta da Cicuta. O referido vazadouro não dispunha, na época, de nenhum controle dos resíduos ali despejados e, entre outros, se destacava o vazamento diário de chorume no rio Brandão (afluente da margem direita do rio Paraíba do Sul) que banha a Floresta da Cicuta e é despejado no rio Paraíba do Sul. Em 1994, a extinta Fundação Estadual de Engenharia do Meio Ambiente (FEEMA), com a intervenção do Estado do Rio de Janeiro, firmou um TAC com a Companhia Siderúrgica Nacional (CSN) para a adoção de uma centena de ações mitigadoras aos danos ambientais causados pela CSN, com três medidas compensatórias. 
Figura 1: Vista parcial do lixão municipal antes das medidas solicitadas pelo Ministério Público Federal e Estadual na Ação Civil Pública. Atentar para a disposição inadequada dos resíduos e para a lagoa de acúmulo de chorume à jusante da pilha de resíduos.

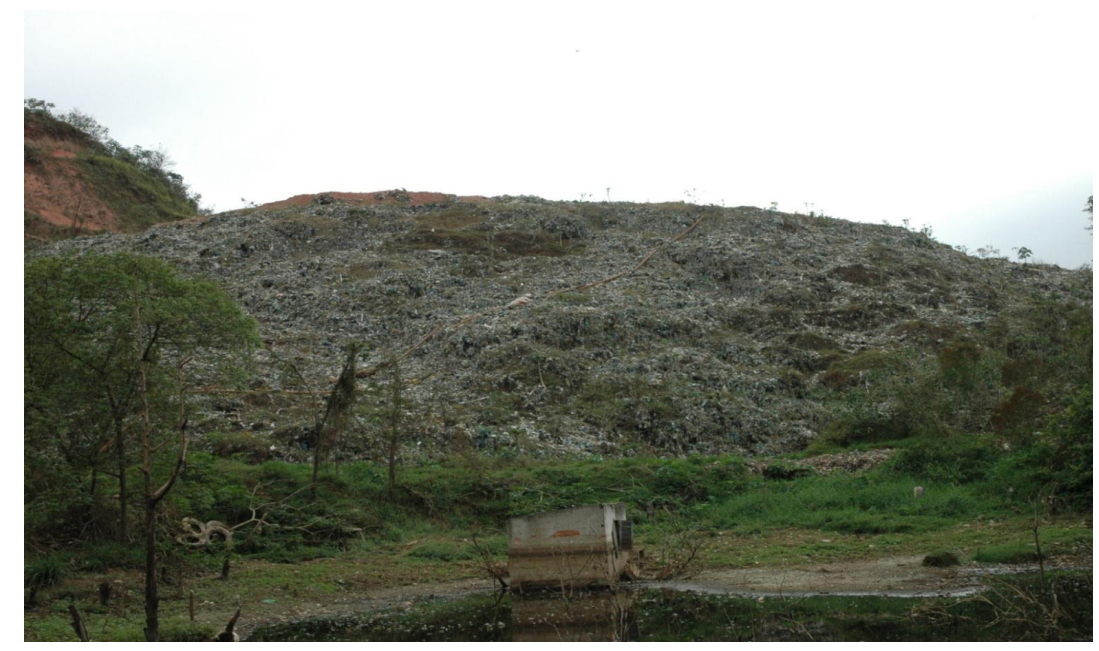

Fonte: PMVR, 2011.

Dentre as medidas compensatórias propostas, destaca-se a construção do aterro sanitário de Volta Redonda, para solucionar a disposição inadequada de resíduos sólidos urbanos no município. 0 aterro sanitário proposto seria construído na área que abriga o lixão existente e, segundo a consulta prévia feita pela Prefeitura Municipal de Volta Redonda à FEEMA, através do ofício $n^{\circ} 448 / 99$, o órgão não relatou impedimentos de ordem legal e ambientais para a localização do aterro sanitário no local. Assim, a área escolhida foi declarada de utilidade pública para fins de desapropriação, em 2000, pelos decretos anteriormente mencionados.No dia 2 de julho de 2001, a FEEMA emitiu a Licença Prévia (LP) $n^{\circ}$ 047/2001 do empreendimento solicitado, com 26 restrições; posteriormente, em 25 de fevereiro do ano de 2002, a Licença de Instalação (LI) nº 097/2002 foi emitida, enumerando 17 restrições.

A área em tela está localizada no entorno da ARIE da Floresta da Cicuta, em virtude do descumprimento ao disposto no parágrafo único do art. $2^{\circ}$ da Resolução CONAMA $n^{\circ} 13$, de 06/12/1990. 0 Instituto Brasileiro do Meio Ambiente e dos Recursos Naturais Renováveis (IBAMA), em 25/09/2002, lavrou, em nome do Município de Volta Redonda, o Auto de Infração nº 351984 e Termo de Embargo/ Interdição ${ }^{\circ} 223064$, referente ao aterro sanitário em construção.

A Prefeitura Municipal de Volta Redonda não se ateve aos critérios técnicos e se mostrou indiferente a vários impactos ambientais negativos de grande magnitude que aconteceriam em virtude da implantação do empreendimento - aterro de brejos existentes nas depressões, invasão de matas em estágio médio de regeneração e falta de anuência do IBAMA para ocupação da zona de amortecimento da ARIE da Floresta da Cicuta. A ocorrência desses impactos ambientais negativos anteriormente descritos deveria ser considerada pela PMVR, com propostas de discussão com os outros órgãos ambientais envolvidos, FEEMA e IBAMA, com possibilidades de mitigar os impactos e, talvez, para procura de outro local mais adequado para abrigar o aterro sanitário. Vale ressaltar que, em 30 de novembro de 2005, o Ministério Público Federal (MPF) e o Ministério Público Estadual (MPE), através do processo nº 2003.51.04.002.992-9, celebraram um novo TAC com a Prefeitura Municipal de Volta Redonda, visando à adoção de medidas emergenciais na área do vazadouro para remediação dos impactos ambientais verificados, onde se destacam, entre outras, a caracterização físico-química do chorume gerado, o retaludamento da massa de resíduos para diminuição do risco de erosão e a condução adequada das águas pluviais, a não disposição de animais mortos e rejeitos de açougues e matadouros a céu aberto e 
a promoção da disposição final dos resíduos de saúde em valas impermeabilizadas com solo-cimento, argila compactada ou manta plástica resistente.

Carli \& Lopes (2016), em sua pesquisa, atestam que o TAC não foi cumprido e que a Justiça Federal determinou a aplicação de multa pessoal para o representante legal do município de Volta Redonda, através do processo 0001167-25.2010.4.02.5104. Em consulta à SMMA de Volta Redonda, através de ofício, informou-se, em 09/02/17, que se requereu a Licença Ambiental de Recuperação (LAR) para a remediação de vazadouro, através do protocolo $n^{\circ} \mathrm{E}$ 07/002.09815/2015, e que se encontra em análise junto ao órgão.

\subsection{A construção do Plano Municipal de Gerenciamento Integrado de Resíduos Sólidos de Volta Redonda}

Com a edição da Política Nacional de Resíduos Sólidos, em agosto de 2010, a Prefeitura Municipal de Volta Redonda iniciou o processo de encerramento de seu lixão e deu início à elaboração de seu Plano Municipal de Resíduos Sólidos. Diante desse novo cenário e da alta complexidade técnica que circunda o tema, o Município de Volta Redonda contratou a Ecologus Engenharia Consultiva Ltda., para apoiar a elaboração do Plano Municipal de Saneamento Básico (PMSB) e o Plano Municipal de Gerenciamento Integrado de Resíduos Sólidos (PMGIRS), buscando estabelecer a melhor Política Municipal para o Saneamento Básico em seu território, além de atender às diretrizes estabelecidas pela Legislação Federal sobre o tema, sempre considerando as diretrizes e os recursos financeiros disponibilizados pelos Governos Federal e Estadual.

Segundo Setta (2016), o município de Volta Redonda, atendendo determinação do Ministério Público Federal (MPF), contida no TAC n² 2003.5104002992-9, passou a enviar seus resíduos sólidos urbanos, desde 28 de maio de 2012, ao Centro de Tratamento de Resíduos (CTR), localizado em Barra Mansa, com o intuito de diminuir a ocorrência de impactos ambientais negativos provenientes da omissão da PMVR, no que se refere ao descumprimento parcial do termo acima citado.

\subsection{Ações pontuais da Prefeitura Municipal de Volta Redonda na Gestão de Resíduos previstos na PNRS}

Neste capítulo, serão relacionadas às ações concretas da PMVR na gestão de resíduos sólidos. Através da SMAC, a Prefeitura Municipal de Volta Redonda apoia a Cooperativa Popular dos Agentes do Meio Ambiente do município de Volta Redonda (Reciclar/VR), que se situa à rua $35, n^{\circ} 650$, bairro Vila Santa Cecília, cooperativa sem fins lucrativos que reúne catadores de rua e que tem como foco a coleta de recicláveis (garrafas PET, plásticos em geral, papel, papelão, jornal, revistas, sucata ferrosa, alumínio e vidro), para posterior pesagem e venda a atravessadores que enviarão os devidos materiais a empresas especializadas em reciclagem. Ressalta-se que o apoio da SMAC à cooperativa visa à inclusão social de catadores, poismuitos deles eram dependentes químicos, alcoólatras e andarilhos que não conseguiam uma colocação no mercado de trabalho.

Segundo informações do gerente de divisão da SMAC, cedido para executar a administração da cooperativa, a entidade foi criada em 2009 e recebe em média cerca de 60 a 65 toneladas de recicláveis por mês, sendo que a maioria do material coletado é papelão (aproximadamente, 27 toneladas/mês).

A cooperativa conta com trinta e dois cooperados encarregados da triagem do material recolhido e vinte catadores equipados com carrinhos para a coleta nos logradouros públicos que pagam uma cota-parte de $\mathrm{R} \$ 100,00$, para ingresso entidade, recebendo semanalmente, perfazendo uma média de $\mathrm{R} \$ 630,00$ (seiscentos e trinta reais/mês). A Prefeitura Municipal de Volta Redonda disponibiliza dois 
caminhões-baú para auxiliar na coleta dos recicláveis, duas prensas, uma balança eletrônica, uma balança mecânica, um elevador hidráulico, luz, água, telefone e dois funcionários, incluindo o entrevistado.

A Reciclar/VRconta também com o apoio de outros parceiros (Café Faraó, Café Favorito, Supermercados Floresta, Casa de Saúde São Camilo, Postos AP, SAAE/VR, Nova Gráfica, Associação dos Pais e Amigos de Excepcionais- APAE e Transpetro) que doam mensalmente materiais recicláveis para auxiliar nos ganhos dos cooperados. Além dessas parcerias, vinte e cinco escolas municipais fazem palestras educativas sobre o projeto denominado "Aprendendo a Reciclar", enfatizando a importância da separação dos resíduos sólidos urbanos. A PMVR providenciou a construção de um galpão para facilitar a triagem dos materiais recicláveis coletados, sua pesagem, marcação dos fardos e depósito, tendo em vista que o espaço era reduzido e dificultava as ações de recebimento do material. A reforma executada visa à melhoria do layout da edificação, tendo em vista que o local anteriormente abrigava um canil municipal e a estrutura teve que ser adaptada para receber os cooperados e os materiais coletados.

A referida cooperativa não possui licenciamento ambiental, já que a atividade em tela não é potencialmente poluidora. A coleta seletiva no município de Volta Redonda começou em 15 de março de 2009 e, segundo informações colhidas junto ao Coordenador do Programa de Coleta Seletiva e do Projeto "Florestas de Volta", da Secretaria Municipal de Serviços Públicos, recolhe-se em torno de 5 toneladas de recicláveis por dia e cerca de sete toneladas em dias posteriores a festas populares, dia dos pais, dia das mães, dia dos namorados, Páscoa, Natal e outras datas comemorativas que geram muito lixo seco (plástico, garrafas PET, latas, vidro, papel e papelão). 0 material reciclado que mais se recolhe é o papel e o papelão que juntos correspondem a, aproximadamente, $50 \%$ do total de recicláveis coletados. Além da Reciclar-VR, os resíduos recicláveis são também direcionados a duas outras cooperativas de catadores, a Folha Verde e a Cidade do Aço que, juntamente com a Reciclar-VR, coletaram, triaram e destinaram 523,24 toneladas para a reciclagem,no ano de 2013 (PMIGRS, 2015). Das 523,24 toneladas recolhidas de recicláveis, a SMSP (2013) aferiu que 308,45 toneladas correspondem a papel e papelão; 113,66 toneladas são de plástico; 36,38 toneladas, de vidro; 52,82 toneladas, de metais; e 11,92 toneladas, de outros materiais diversos. Todos os bairros são atendidos pela coleta seletiva que utilizava os caminhões compactadores e que, atualmente, emprega quatro caminhões-gaiola, sendo dois para atendimento no período diurno e dois para o turno noturno. A SMOSP fornecia, no início da coleta seletiva, sacos plásticos transparentes para a armazenagem dos recicláveis que são, posteriormente, recolhidos pelos caminhões do programa e encaminhados para a Reciclar/VR e Folha Verde em proporções semelhantes ( $30 \%$ para cada cooperativa) e o restante é vendido para custear a compra dos sacos plásticos empregados na coleta seletiva.

A prefeitura começou a coleta seletiva sem informação prévia à população voltarredondense e, até hoje, ainda existem pessoas que desconhecem a existência de tal programa e sua metodologia e objetivos. Segundo a pesquisa realizada na SMOSP, a prefeitura pretende melhorar a divulgação desse programa e vai providenciar a confecção de 100.000 folders em papel reciclado, para serem tempestivamente distribuídos à população do município, além de providenciar a adesivação dos caminhões-gaiola utilizados na coleta dos recicláveis, sonorização e uniforme diferenciado para os garis que trabalham diretamente na função. Não existem hoje, no município, Postos de Entrega Voluntária (PEVs) ou Locais de Entrega Voluntária (LEVs), para facilitar e fomentar a entrega de recicláveis e tampouco incentivos governamentais para estimular a participação da população voltarredondense nessa empreitada. Segundo o coordenador entrevistado, também não existe nenhum ponto público para coleta de lâmpadas fluorescentes, pilhas e baterias, remédios vencidos e pneus, que se caracterizam como rejeitos que devem ter sua destinação ambiental correta para evitar mais danos ao meio ambiente.

Os resíduos de estabelecimentos comerciais e prestadores de serviço (RCS) coletados em Volta Redonda correspondem a 18\% dos RSUs gerados no município e totalizam cerca de 37 toneladas por 
dia, segundo levantamento do Plano Estadual de Resíduos Sólidos do Rio de Janeiro (2013), e são coletados juntamente com os RSUs. Os Resíduos de Serviços Públicos de Saneamento Básico (RSB) são aqueles gerados nas atividades de tratamento de água e esgotos sanitários, basicamente compostos por lodos derivados desses processos de tratamento. Existem 06 estações de tratamento de esgoto (ETEs) no município de Volta Redonda designadas: ETE Padre Josimo, ETE Ronaldo Gonçalves, ETE Volta Grande, ETE Vila Rica I, ETE Vila Rica II e ETE Eng. Silvino Streva, que juntas geram um total de 727,6 m³/ano, segundo o Serviço Autônomo de Água e Esgoto de Volta Redonda (2014). É interessante ressaltar que as ETEs Ronaldo Gonçalves e Eng. Silvino Streva utilizam o lodo proveniente de suas respectivas unidades para a fertilização de plantas ornamentais através de leitos de secagem. A Estação de Tratamento de Água (ETA) do Belmonte lança sem tratamento algum o lodo gerado em sua unidade no principal manancial da região o rio Paraíba do Sul.

Os Resíduos de Serviços de Saúde (RSS) são aqueles gerados nas unidades de atençãoà saúde humana e animal, cuja composição básica é a seguinte: resíduos comuns recicláveis; resíduos comuns não recicláveis; resíduos especiais. Os resíduos de serviços de saúde correspondem a 1\% dos RSUs gerados no município, que correspondem a cerca de 2,06 toneladas por dia e 751,9 toneladas por ano, segundo dados do Plano Estadual de Resíduos Sólidos (2013). Nessa seara, é importante destacar que as unidades hospitalares de maior porte não dispõem de Planos Internos de Resíduos de Serviços de Saúde, que acabam sendo coletados pela SMSP e que, consequentemente, geram maiores quantidades de RSSs junto aos RSUs.

Os resíduos de construção civil (RCC) são aqueles gerados nas construções, reformas, reparos e demolições de obras de construção civil, incluídos os resultantes da preparação e escavação de terrenos para obras civis, conforme disposto no artigo 13 da Política Nacional de Resíduos Sólidos. Segundo o diagnóstico de RCC constante do PERS-RJ (2013), o índice de geração per capita de RCC estimado para o Município de Volta Redonda é de 0,456 ton/hab/ano, o que conduz à seguinte geração estimada de 117.504,82 toneladas por ano.A Política Nacional de Resíduos Sólidos classifica como resíduos agrossilvopastoris (RASP) todos os resíduos gerados em atividades rurais, sejam eles resíduos oriundos de atividades domésticas, sejam aqueles gerados nas atividades agropecuárias.

Parte dos RASP são obrigatoriamente sujeitos ao sistema de logística reversa, no qual o fabricante, em especial de embalagens de agrotóxicos, é responsável pela coleta, armazenamento e destinação ambientalmente adequada da embalagem contaminada, conforme reza o artigo 33 da PNRS, a lei federal $n^{\circ} 7.802 / 89$, que trata de Agrotóxicos e a Resolução CONAMA n 465/14, que dispõe sobre os requisitos e critérios técnicos mínimos necessários para o licenciamentoambiental de estabelecimentos destinados ao recebimento de embalagens de agrotóxicos e afins, vazias ou contendo resíduos. No Município de Volta Redonda, a coleta de resíduos domiciliares urbanos abrange tanto a zona urbana quanto a zona rural, em frequências de coleta diferentes, sendo a zona urbana atendida com uma maior frequência dada a maior geração e população. Segundo dados do IBGE de 2010, a população rural do município é de apenas $0,05 \%$.

A coleta dos resíduos domiciliares na área rural é feita 3 (três) vezes por semana, às terças, quintas e sábados. 0 sistema público municipal de transporte e coleta dos resíduos foi estruturado pela Secretaria Municipal de Serviços Públicos de Volta Redonda, denominado 01, 02, 03 e 04 em quatro subsistemas, de acordo com a sua destinação final, sendo que os resíduos sólidos urbanos (RSU), resíduos de estabelecimentos comerciais e prestadores de serviço (RCS), resíduos agrossilvopastoris (RASP), resíduos industriais (fração doméstica), resíduos de serviços de saúde (fração comum) e resíduos de serviços de transporte (RST) são direcionados para o Centro de Tratamento de Resíduos da Haztec em Barra Mansa; o subsistema 02 destina os resíduos domiciliares (fração seca) e os resíduos de estabelecimentos comerciais e prestadores de serviços (RCS), na fração seca, para as três coope- 
rativas de catadores (Folha Verde, Reciclar-VR e Cidade do Aço); o subsistema 03 destina os Resíduos de Serviços de Saúde (RSS), em sua fração especial, para a empresa Servioeste, de Barra do Piraí, para a autoclavagem; e o subsistema 04 coleta os resíduos de construção civil (RCC), os volumosos e os resíduos de poda para o bota-fora municipal, localizado na rodovia Tancredo Neves. Segundo informações da SMMA/VR, prestadas em fevereiro de 2017, esse "bota fora" está localizado nas coordenadas $554.463,73$ E e 7.502.733,18 S, devidamente licenciado pela prefeitura através da Licença Municipal Prévia e de Instalação (LMPI) no 002-05/12, que autoriza a PMVR o recebimento de terra, RCC e volumosos com compactação para nivelamento de área e resíduos de poda.

\subsection{Logística Reversa}

No tocante à logística reversa, prevista no artigo 33 da Política Nacional de Resíduos Sólidos, o PMGIRS (p. 178) da municipalidade se omite e apenas cita que a PMVR deverá se posicionar futuramente sobre a regulamentação desse instrumento para as seguintes tipologias: agrotóxicos, seus resíduos e embalagens, assim como outros produtos cuja embalagem, após o uso, constituam resíduo perigoso; pilhas e baterias; pneus; óleos lubrificantes, seus resíduos e embalagens; lâmpadas fluorescentes, de vapor de sódio e mercúrio e de luz mista; produtos eletroeletrônicos e seus componentes.

Santos e Leite (2016) destacam, em seu trabalho, as iniciativas privadas existentes em Volta Redonda, para a destinação ambientalmente correta dos resíduos passíveis de logística reversa. Segundo essas iniciativas, os pneus são encaminhados à empresa Vincol, desde 2015, que fica responsável pela recepção, guarda desses pneus inservíveis até a retirada por empresa autorizada, porém não constam informações sobre a quantidade destinada de pneus inservíveis no sítio eletrônico da empresa. Os pneus abandonados em vias e logradouros públicos, bem como aqueles utilizados em veículos e equipamentos públicos, são armazenados pela SMSP, segundo informação do PMGIRS do município de Volta Redonda. Quanto aos óleos lubrificantes usados ou contaminados (OLUC), o PMGIRS (p.134, 2015) informa que já é objeto de acordo setorial no âmbito da logística reversa estabelecida pela PNRS, acordo firmado entre o poder público e a Agência Nacional de Petróleo, Gás Natural e Biocombustível (ANP), que é responsável por autorizar qualquer atividade relacionada à fabricação, importação, coleta e rerrefino de óleo lubrificante.

Destaca-se, nesse ínterim, que a empresa Lwart Lubrificantes, associada ao Sindicato Nacional da Indústria do Rerrefino de Óleos Minerais (Sindirrefino), atua na coleta e transporte desse resíduo, fazendo a sua recolha diretamente nos postos de combustíveis, informação essa contida no PMGIRS.

Santos e Leite (2016) apuraram, em sua pesquisa, que os produtos eletroeletrônicos são inicialmente enviados à cooperativa de catadores Reciclar/VR, que recebe esses resíduos, realiza triagem, retirando partes mais nobres para sua comercialização e direciona os materiais restantes para compradores da própria região, mas inexistem informações sobre o montante recebido e comercializado no PMGIRS. A Prefeitura Municipal de Volta Redonda e a empresa Fape Informática se uniram e firmaram um programa de capacitação de ex-presidiários, para utilização dos resíduos eletrônicos para aulas de manutenção de computadores, qualificando-os para a reinserção no mercado de trabalho. As aulas eram realizadas no Patronato da Secretaria de Ação Penitenciária (Rua 2, n 125 , bairro Conforto/Volta Redonda), onde, ainda hoje, é possível realizar a entrega de resíduos eletrônicos para descarte, mas o projeto não teve continuidade e não pode atingir todos os seus objetivos, como levar à informática à população carente do município, promovendo o desenvolvimento educacional, oferendo cursos e realizando doações a instituições de apoio social de equipamentos recuperados (SANTOS; LEITE, 2016).

No tocante a pilhas e baterias, o PMGIRS não relaciona o quantitativo gerado no município e tampouco a tratativa para essa tipologia de resíduo. Quanto às lâmpadas, de vapor de sódio e mercúrio 
e de luz mista, Santos e Leite (2016) levantaram que as lâmpadas queimadas dos órgãos e autarquias ligados à Prefeitura Municipal de Volta Redonda (PMVR) são coletadas e encaminhadas para empresa devidamente autorizada para descontaminação, através da SMSP (PMGIRS, 2015), mas, no Plano, não estão contempladas informações quanto à destinação desse resíduo coletado nas residências. A empresa Certa Material Elétrico, por meio de iniciativa isolada, recebe da população lâmpadas diversas que estão inutilizadas e envia o material coletado para descontaminação, reciclando lâmpadas através do projeto "papa-lâmpadas" que foi contemplado com Certificado de Destinação Final, em 2015 (CERTA, 2016).

\section{RESULTADOS E DISCUSSÃo}

Conclui-se que a gestão de resíduos sólidos em nível municipal é ainda incipiente e está mal estruturada, mostrando a urgência de seimplementar o Plano Municipal de Resíduos Sólidos pela aprovação da lei que trata do PMGIRS; que a coleta seletiva na cidade ainda se encontra deficitária, pois grande parte da população desconhece sua existência e tampouco sua operacionalização e importância, para a proteção do meio ambiente e para a gestão de resíduos em nível local. 0 estudo também demonstra a inexistênciade postos de entrega voluntária (PEVs) para o recebimento de recicláveis, que poderiam ser revertidos em renda para as cooperativas de catadores existentes e para aumentar a vida útil do Centro de Tratamento de Resíduos de Barra Mansa, local de destinação dos resíduos sólidos urbanos oriundos de Volta Redonda; e que as três cooperativas de catadores (Reciclar/VR, Folha Verde e Cidade do Aço) existentes em Volta Redonda estão em dificuldades pela insuficiência de produtos recicláveis a elas destinadas e igualmente pela dificuldade na segregação desses recicláveis pela falta de consciência da população na separação dos resíduos.

As pesquisas apuraram que a participação popular voltarredondense, com vistas à gestão compartilhadana gestão de resíduos, ainda é muito discreta e deficitária e eleva os custos referentes à sua coleta, na medida em que aumenta sensivelmente a geração de resíduos per capita, pelo transporte dos resíduos até a sua disposição final; e que a fiscalização ambiental, para coibir o despejo irregular de resíduos em locais inadequados na cidade, é preocupante, pois o número insuficiente de fiscais ambientais compromete os serviços de vigilância ambiental, causando sérios danos ao meio ambiente. Torna-se imprescindível a criação de um fórum municipalpermanente para discussão e aperfeiçoamento da gestão de resíduos em nível local.

\section{RECOMENDAÇõES}

Faz-se extremamente necessário aprovar com urgência o Plano Municipal de Resíduos Sólidos, junto à Câmara Municipal de Volta Redonda, visando ao estabelecimento formal da política ambiental local referente à gestão de resíduos, com a participação da sociedade, empresas, Poder Público, Cooperativas de Catadores, Organizações do Terceiro Setor e demais interessados, em cumprimento a lei federal $n^{0} 12.305 / 10$ (PNRS). É iminente apoiar formal e continuamente as três cooperativas de catadores existentes no município, de forma que possam efetivamente subsistir com a segregação e posterior venda dos recicláveis coletados nos logradouros pelas próprias e pelos caminhões-gaiola hoje utilizados é. Faz-se necessário também fomentar a Educação Ambiental de caráter formal e não formal preconizadas pela lei federal no 9.795/99 (Política Nacional de Educação Ambiental) no município, de forma que a sociedade em geral tenha ciência da importância de sua participação na gestão compartilhada dos resíduos, dos impactos ambientais negativos gerados pela inadequada disposição, de forma a colaborar efetivamente na coleta seletiva existente, aumentando o envio de recicláveis às cooperativas de catadores e, consequentemente, diminuindo a geração de resíduos sólidos urbanos ao Centro de Tratamento de Resíduos de Barra Mansa. Recomenda-se também executar a instalação 
de Postos de Entrega Voluntárias ou Locais de Entrega Voluntárias em diversos locais da cidade, para incentivar a entrega de recicláveis e resíduos da logística reversa, a fim de facilitar a coleta, sua devida reciclagem e encaminhamento aos fabricantes, conforme reza o artigo 33 da Política Nacional de Resíduos Sólidos. Há necessidade imediata do Poder Público Municipal realizar concurso público para fiscais ambientais e/ou de postura para suprir o déficit desses profissionais; aperfeiçoar o sistema de vigilância ambiental, com o intuito de diminuir a ocorrência de crimes ambientais, como disposição inadequada de resíduos em terrenos baldios, faixas marginais de proteção, mananciais e outros de natureza similar, cumprindo integralmente as medidas mitigadoras estabelecidas na Licença Ambiental de Recuperação $n^{\circ}$ E-07/002.09815/2015 do INEA, referente ao encerramento do lixão municipal, para diminuição e/ou eliminação dos impactos ambientais negativos sobre a unidade de conservação ARIE Floresta da Cicuta.

\section{REFERÊNCIAS}

AIEX, G. A. \& CARLI, A. A Tratabilidade do lixiviado do aterro controlado de Volta Redonda - RJ e legislação aplicável. $1^{\circ}$ Seminário de Políticas Públicas e Meio Ambiente. Universidade Federal Fluminense, polo de Volta Redonda, campus Aterrado. 2016.

BANDEIRA AMARO, A \& VERDUM, A. Política nacional de resíduos sólidos e suas interfaces com os espaços geográficos: entre conquistas e desafios. Porto Alegre: Editora Letra 1, 2016. 396p.

BOTKIN, D. B. \& KELLER, E. A. Ciência Ambiental: terra, um planeta vivo. 7. ed. Rio de Janeiro. Editora LTC, 2011. 681p.

BRASIL. Lei Federal nº 9.795/99. Política Nacional de Educação Ambiental. Brasília. Distrito Federal.

Lei Federal n 12.305/10. Política Nacional de Resíduos Sólidos. Brasília. Distrito Federal.

Perfil do Município de Volta Redonda. Rio de Janeiro, 1991. 98p.

GURGEL JÚNIOR, F. J. Gestão ambiental municipal: estudo de caso de Volta Redonda/RJ, no período 2005-2012. 149p. Tese (Doutorado) Universidade Federal Rural do Rio de Janeiro, 2012.

Lei Municipal $n^{\circ}$ 4.430/08. Dispõe sobre a reciclagem e inclusão socioambiental dos catadores informais de materiais recicláveis e dá outras providências. Volta Redonda/RJ.

Lei Municipal $n^{\circ}$ 4.497/08. Dispõe sobre a substituição do uso de sacos plásticos de lixo e de sacolas plásticas, por sacos de lixo ecológicos e sacolas ecológicas e dá outras providências. Volta Redonda/RJ.

Lei Municipal $n^{\circ} 4.677 / 10$. Dispõe sobre o reaproveitamento do material orgânico proveniente da poda de árvores e da coleta de lixo de feiras-livres no âmbito do município e dá outras providências. Volta Redonda/RJ.

LEITE, E. A. \& SANTOS, C. M. Diagnóstico do plano municipal de gestão integrada de resíduos sólidos de Volta Redonda/RJ com ênfase na logística reversa obrigatória. Monografia de conclusão de curso em Engenharia Ambiental. Centro Universitário de Volta Redonda/UniFOA, 2016. 77 p.

MACHADO, C. J. S. Gestão de águas doces no Brasil. Rio de Janeiro: Ed. Interciência, 2004. 372p. 
MAHLER, C.; ARAUJO de F. V. \& PARANHOS, R. Poluição: poluição aquática e resíduos sólidos. Rio de Janeiro: Editora Aquarius, 2002. 132p.

Ministério do Meio Ambiente-MMA/Ministério da Educação-MEC/Instituto Brasileiro de Defesa do Consumidor-IDEC. Consumo sustentável: manual de educação. Brasília. 2005. 160p.

PERS - Plano Estadual de Resíduos Sólidos, 2013. Disponível em: <http://download.rj.gov.br/ documentos/10112/1941396/DLFE-66812.pdf/PLANO ESTADUALDERESIDUOSSOLIDOSDORIODE JANEIRO.pdf>. Acesso em: $10 \mathrm{dez} .2016$.

PMGIRS - Plano Municipal de Gestão Integrada de Resíduos Sólidos de Volta Redonda, 2015. Disponível em: <http://www.portalvr.com/projetos/saneamento/ mod/consulta_publica_2015/pdf/DOC3_PMGIRS. pdf>. Acesso em: 02 nov. 2016.

SETTA, B. R. S. Análise preliminar da degradação ambiental na área do lixão do município de Volta Redonda- RJ. Anais do $5^{\circ}$ Simpósio de Gestão Ambiental e Biodiversidade. 2016. 09p.

SOUZA, D. C. 0 meio ambiente das cidades. São Paulo: Editora Atlas, 2010. 219p.

VESELIND, P. A. \& MORGAN S. M. Introdução à engenharia ambiental. 2. ed. São Paulo: Editora Cengage Learning, 2011. 438p.

YOSHIDA, C. Competência e as diretrizes da PNRS: conflitos e critérios de harmonização entre as demais legislações e normas. In: JARDIM, A; YOSHIDA, C \& MACHADO FILHO, J. V. Política nacional, gestão e gerenciamento de resíduos sólidos. Barueri/SP. Editora Manole. 2012. pp. 03-38.

\section{Sítios Eletrônicos Consultados}

www.abrelpe.com.br (Associação Brasileira das Empresas de Limpeza Pública e Resíduos Especiais) acesso em 10/12/2015.

www.cempre.com.br (Site do Compromisso Empresarial para a Reciclagem, acesso em 10/10/10).

www.ibge.gov.br (Site do Instituto Brasileiro de Geografia e Estatística, acesso em 09/07/10).

www.portalvr.com.br (Site Oficial da Prefeitura Municipal de Volta Redonda - PMVR, acesso em 02/07/2009).

www.saaevr.com.br (Site do Serviço Autônomo de Água e Esgoto de Volta Redonda, acesso em 14/1 1/11).

www.sinir.gov.br (Site do Sistema Nacional de Informações sobre Resíduos, acesso em 13/02/17).

www.snis.gov.br (Site do Sistema Nacional de Informações sobre Saneamento, acesso em 14/11/11). 